\title{
AS FORMAS DE PRODUÇÃO NO RIO GRANDE DO SUL E SUA RELAÇÃO COM A EMIGRAÇÃO RURAL
}

\section{Rosa Maria Vieira Medeiros* \\ e-mail: $\underline{\text { rmvmedeiros@yahoo.com.br }}$}

\section{RESUMO}

A emigração rural no Rio Grande do Sul tem se caracterizado por uma forte aceleração a partir dos anos sessenta muitas vezes associada ao processo de modernização pelo qual passou o estado. No entanto ao se propor uma regionalização do estado por suas formas de produção considerando sua estrutura fundiária, seu processo histórico de povoamento e colonização, suas formas de produção agropastoril e sua produção para analisar o processo de emigração rural identificou-se que o fator pressão demográfica também é responsável pela aceleração da emigração rural assim como a modernização da agricultura. Ficou então evidente que a predominância de um ou do outro fator de expulsão (modernização e pressão demográfica) está diretamente relacionada à uma forma de produção específica.

Palavras-chaves: emigração rural, formas de produção, Rio Grande do Sul, pressão demográfica, modernização da agricultura.

\section{RÉSUMÉ}

L'émigration rurale dans l'Etat du Rio Grande do Sul est caractérisée par une forte accéleration à partir des années soixante et la plus part est associée au processus de modernisation par lequel l'Etat a passé. Cependant la proposition d'une régionalization par les formes de production, tout en considerant sa structure foncière, son processus historique de peuplement et colonisation, ses formes de production agropastoril et sa production, pour analyser le processus d'émigration rurale il a été identifié que le facteur pression démographique est aussi responsable pour l'accelaration de l'émigration rurale ainsi que la modernisation de l'agriculture. Donc il a été evident que la prédominance d'un ou d'autre facteur d'expulsion (modernisation et pression demographique) est rapporté à une forme de production spécifique

Mots--clés: émigration rurale, formes de production, Rio Grande do Sul, pression démographique, modernisation de l'agriculture.

\footnotetext{
* Prof ${ }^{a}$ Dr $^{\mathrm{a}}$ do Departamento de Geografia do IG da UFRGS e Coordenadora do Programa de PósGraduação em Geografia da UFRGS.
} 


\section{INTRODUÇÃO}

O estudo das migrações no Rio Grande do Sul continua a ser fundamental considerando as mudanças sociais e econômicas pelas quais passou o setor rural do estado. A redução de seu efetivo populacional rural vem acontecendo desde a década de 1950, quando se acentuou o processo de urbanização e conseqüentemente o crescimento da população urbana que a partir desta década foi, inclusive, superior ao crescimento da população total do Estado. A população rural, ao contrário da urbana, foi sofrendo uma redução, chegando a um decréscimo de 47,51\% considerando o período de 1950 a 2000. (tabela 1).

Tabela 1

\section{População - Rio Grande do Sul}

\begin{tabular}{|l|c|c|c|c|c|c|c|}
\hline \multicolumn{1}{|c|}{ Total } & $\underline{2000}$ & $\underline{1996}$ & $\underline{1991}$ & $\underline{1980}$ & $\underline{1970}$ & $\underline{1960}$ & $\underline{1950}$ \\
\hline Urbana & 8.317 .984 & 7.579 .977 & 6.996 .542 & 5.250 .024 & 3.554 .239 & 2.445 .774 & 1.421 .980 \\
\hline Rural & 1.869 .814 & 2.054 .711 & 2.142 .128 & 2.523 .825 & 3.110 .602 & 3.003 .049 & 2.742 .841 \\
\hline Percentual & \multicolumn{7}{|c|}{} \\
\hline Urbana & 81,65 & 78,67 & 76,56 & 67,53 & 53,33 & 44,89 & 34,14 \\
\hline Rural & 18,35 & 21,33 & 23,44 & 32,47 & 46,67 & 55,11 & 65,86 \\
\hline
\end{tabular}

Notas: 1 - Para 1950: População presente

2 - Para 1960 até 1980: População recenseada

3 - Para 1991 até 2000: População residente

Fonte: Censo Demográfico

Neste período o movimento populacional conferiu ao Rio Grande do Sul características predominantemente emigratórias modificando seu perfil típico de Estado receptor de população. Esta característica permaneceu até por volta da década de 1920 quando então se reverte o processo, com a saída de pessoas para outras áreas do país e com os deslocamentos internos dentro do próprio Estado. Segundo MOREIRA E COSTA (1982:64), pode-se estabelecer as seguintes fases para a migração no RS:

Século XVII - fluxo (e refluxo) de jesuítas espanhóis e de portugueses;

Século XVIII - ocupação das áreas de campo por lagunenses, paulistas, etc; 
Século XVIII - XIX - imigração açoriana para a faixa litorânea e o vale do baixo Jacuí;

Século XIX - imigração alemã (1824 em diante) para os vales e baixa encosta, e de italianos (a partir de 1875) para a alta encosta do planalto;

Primeira metade do século XX - migração interna das velhas colônias para o alto Uruguai;

Século XX - (principalmente a partir de 1950), êxodo rural para os principais centros urbanos do Estado, especialmente a Grande Porto Alegre, e migração rural-rural das áreas de expansão colonial (alto Uruguai) para outros estados.

Estas etapas demonstram a mobilidade da população camponesa inicialmente construindo seu território e ocupando-o intensivamente e posteriormente, em decorrência de novos fatores, abandonando-o em busca de outros onde se reiniciasse sua nova territorialização.

MARX, já considerava a população do campo como "uma fonte de superpopulação relativa que não se esgota mais". Afirmava que "desde que a produção capitalista se apoderou da agricultura ou pelo menos do grau em que o fez, a acumulação de capital em funcionamento acarretou a diminuição absoluta na procura de população agrícola". (1980: 167)

Com a expansão do processo de acumulação, intensificou-se a subordinação das diferentes formas de produção sob a égide do capital, acarretando "mudanças nas relações de trabalho, pela desvinculação do trabalhador aos meios de produção, sobremodo a terra, tornando-se então disponível às necessidades da expansão capitalista ou na manutenção de formas pré-capitalistas de produção, contanto que sejam subordinadas à dinâmica própria dessa expansão” (OSÓRIO, 1980: 1146). Surge, então, o trabalhador assalariado no campo cujas "condições caem abaixo do nível normal da classe operária, encontrando aí, o capital, uma grande base de exploração” (MARX, 1980: 167).

Este trabalhador, desta forma, é um candidato forte a abandonar o campo diante de tamanha força repulsora. Entretanto, também o camponês que ainda detém a posse da terra é um candidato em potencial a emigração, pois a pequena propriedade familiar, constitui uma forma de exploração que concilia a organização familiar com a agricultura e que "não só fornece braços para seu próprio uso como lhes sobram alguns disponíveis, criando assim na pessoa dos filhos uma reserva de operários que não tardará a abandonar o campo" (KAUTSKY, 1972). 
A posse da terra, no entanto, não é suficiente por si só para fixar o homem no campo, pois o seu empobrecimento atua como fator de expulsão independente desta posse, conduzindo ao que afirma VERGOPOULOS (1977: 129) de que a agricultura camponesa constitui um terreno maldito onde o trabalho leva ao empobrecimento.

Entretanto, BAGU E PALERMO (1980), vêem como o mais importante dos fatores de expulsão da população rural, a existência de grandes propriedades. Justificam, em parte, a pobreza e a miséria do camponês pela presença do binômio latifúndiominifúndio ao lado das imposições do mercado externo em relação às mudanças agrícolas.

No que se refere à agricultura brasileira, SORJ (1980:12), observou que as transformações, principalmente quanto às relações de produção, em nada alteram a estrutura fundiária. Estas transformações direcionam a agricultura no sentido de uma 'depuração' das relações existentes, chegando a configurar, em alguns casos, grandes empresas agrícolas tipicamente capitalistas, fortalecendo os produtores capitalizados. Ao mesmo tempo ocorre a geração de uma massa de pequenos produtores pauperizados e crescentemente marginalizados pelos grandes circuitos produtivos, em função de sua baixa produtividade.

Já OSÓRIO (1980: 1149), por sua vez, vê na instabilidade dessas relações de trabalho um dos fatores que acentuam a mobilidade espacial brasileira. Sendo essa mobilidade seletiva, a força de trabalho não-qualificada tem menos poder para defender seu direito de ficar.

No Rio Grande do Sul se fazem presentes alguns dos elementos da transformação do setor rural citados: o binômio latifúndio-minifúndio, a depuração das relações de produção, e a pauperização dos camponeses. Porém, a aplicação do sentido causal migratório desses elementos a qualquer contexto, é questionável (FANDINO, 1978). Por exemplo, nem sempre é válido se falar da penetração de relações capitalistas como fator de emigração. Trata-se de uma postura metodológica dialética discutida por exemplo em GRAMSCI, quando critica o que ele chama de "positivismo Marxista". Segundo esta postura metodológica dialética, não se procura normas ou leis que relacionem causalmente e em qualquer contexto, certos elementos entre si, como no caso presente, a dinâmica demográfica com as formas de produção. Ao contrário, procura-se aqui diferenciar contextos (formas de produção no caso) onde as relações causais entre fenômenos variam. Neste caso, se procura trabalhar na direção de uma especificação dos efeitos migratórios (positivos ou negativos) da estrutura fundiária, da 
dinâmica demográfica e da penetração do capitalismo, particulares às formas de produção historicamente constituídas no setor agrário gaúcho.

\section{NA BUSCA DE UMA CARACTERIZAÇÃO PARA A EMIGRAÇÃO RURAL}

Caracterizar a emigração rural pode parecer ser uma simples busca de fatores que a determinem mas é fundamental encontrar relações entre estes fatores e assim ter uma melhor compreensão do processo.

Para BRUM (1988: 174), o avanço do processo de modernização da agricultura acentuou dois tipos de migrações: a migração dos marginalizados do processo produtivo (peões, agregados e minifundiários) expulsos do campo em direção às cidades (êxodo rural); e a migração de algumas centenas de empresários rurais mais ou menos bem sucedidos que saem em busca de novas terras ao se esgotarem as possibilidade de adquiri-las.

Já SINGER (1980:224) considera que os fatores de expulsão são de duas ordens: fatores de mudança, que decorrem da introdução de relações capitalistas nestas áreas, a qual acarreta a expropriação de camponeses, a expulsão de agregados, parceiros e outros agricultores não proprietários, tendo por objetivo o aumento da produtividade do trabalho e a conseqüente redução do nível de emprego; fatores de estagnação, que se manifestam sob a forma de uma crescente pressão populacional sobre uma disponibilidade de áreas cultiváveis que podem ser limitadas tanto pela insuficiência física da terra aproveitável quanto pela monopolização de grande parte da mesma pelos grandes proprietários.

BAGU PALERMO (1980: 582) vêem a emigração rural como conseqüência do binômio latifúndio-minifúndio, onde o primeiro, mesmo sendo produtivo é pouco absorvedor de mão-de-obra, e o segundo, independente da produtividade da terra, não dá emprego a toda mão-de-obra disponível, pela simples razão de se tratar de uma agricultura para autoconsumo.

Estes postulados relativos á questão migratória afirmam, então, de maneira genérica, a existência de efeitos de certas variáveis causais a todas as instâncias concretas, independentemente da presença de outros fatores ou condicionantes. Assim:

Para SINGER, o capitalismo sempre produz emigração expulsiva (fator de mudança), pois ao objetivar um aumento de produtividade em busca de maiores lucros reduz, drasticamente, os níveis de emprego. Para BRUM, a modernização da agricultura 
é que sempre provoca a emigração rural (considerando que essa modernização é um fator de mudança na agricultura, em função das modificações tanto tecnológicas como sociais, essa afirmação vem ao encontro do que disse SINGER). No entanto, SINGER também coloca que a permanência da população rural nas formas tradicionais da agricultura (estagnação), ligada à falta de disponibilidade de terras, é sempre um fator expulsivo.

Da mesma forma como SINGER, BAGU e PALERMO também colocam que a agricultura tradicional de subsistência atua sempre como fator de expulsão da população rural.

Porém, pode-se perguntar:

É sempre que a modernização expulsa? E a estagnação, também expulsa sempre? Há condições em que esses fatores alteram o seu sentido causal? Especialmente: é possível que existam 'interações', entre esses fatores, que possam inclusive alterar o sentido (positivo ou negativo) das relações causais?

Observa-se então, o caso específico da pecuária desenvolvida na campanha gaúcha, e que sabidamente é uma atividade que por suas características extensivas necessita de pouca mão-de-obra. Ao se desenvolver nessa área uma agricultura moderna, provavelmente será necessário um número maior de empregados do que até então utilizado pela pecuária. Portanto, modernizando a atividade dominante dessa área, a expulsão da população rural não será tão drástica quanto na situação da atividade anterior, apesar das características capitalistas da mudança em questão. Dito de outra forma, a penetração da agricultura moderna no contexto da pecuária pode gerar novos empregos e estabelecer um certo equilíbrio com os efeitos explosivos de outros fatores tais como a dinâmica demográfica e a atração urbana.

Já na área de domínio da pequena propriedade, a modernização capitalista expulsa, pois é claro que ocorre uma diminuição da necessidade de mão-de-obra em função das novas tecnologias ali aplicadas. Mas, e se no entanto, a pequena propriedade se mantiver atrelada à uma agricultura tradicional, é bem provável que a expulsão se dê com menor força pela ausência de tecnologias poupadoras de mão-de-obra. Ainda neste contexto da pequena propriedade tradicional, a pressão demográfica ali existente pode também produzir efeitos de expulsão, apesar de haver uma tolerância de excedentes de mão-de-obra traduzidos em desemprego disfarçado (de formas a permitir a subsistência de todos), em lugar da simples maximização do lucro através da racionalização do uso de mão-de-obra. 


\section{EMIGRAÇÃO E FORMAS DE PRODUÇÃo}

Para abordar a questão dos contextos e interações onde se aplicam os princípios causais explicativos da migração, vai se trabalhar aqui com o conceito de forma de produção.

Por forma de produção se entende aqui, formas de organização primária, ou seja que representam um nível de agregação teórico menor que o Modo de Produção, e que simultaneamente são elementos tanto determinantes do sistema maior como determinados por ele (FRIEDMAN, 1983; FANDIÑO, 1978). A conceituação forma de produção se faz necessária para se referir a sistemas de organização da produção, em uma escala muito mais reduzida que aquela dos Modos de Produção, portanto, estas formas de organização não podem ser designadas por este mesmo conceito. Assim, quando se considera uma fazenda capitalista, não está se considerando todo o capitalismo, mas apenas uma parte dele. Esta parte evidencia a existência (e a interferência) desse todo, no espaço em questão. Esta fazenda, então, não é um modo de produção, mas apenas uma forma de produção.

A partir das formas de produção identificáveis no Estado, as quais desempenham aqui o papel de unidade de análise, considera-se inicialmente, a emigração em questão, segundo três fatores ou variáveis gerais que estão diferentemente associadas com essas formas de produção. Esses fatores ou variáveis são: a pressão demográfica, a modernização capitalista, e a atração urbana (FANDIÑO, 1978).

A modernização da agricultura, segundo BRUM, além de ser o processo de mecanização e tecnificação da lavoura (medido geralmente através dos índices de máquinas, equipamentos, implementos e insumos modernos utilizados), também é definida como o processo que provoca modificações nas relações sociais de produção, implicando numa maior integração entre produtor e produção tanto no mercado quando na racionalidade do lucro. Em outras palavras, com a modernização o objetivo da produção agropecuária passa a ser o lucro através do qual vai se processar a acumulação. Assim, com o avanço do processo de modernização ocorre a chamada ‘industrialização da agricultura' ou a 'industrialização do campo’ (BRUM, 1988: 60).

A pressão demográfica, no sentido aqui utilizado se refere a relação homemterra, ou seja na disponibilidade de terras em relação a mão-de-obra também disponível na unidade produtora. É a pressão populacional sobre uma disponibilidade de áreas cultiváveis (FANDIÑO 1978; SINGER 1980). 
A atração urbana, porém, não é incluída no modelo de variáveis explicativas. Isto porque, sem deixar de admitir que a atração urbana seja um fator, talvez de muita importância para a migração rural-urbana no Estado, supõe-se que os seus efeitos não são 'interativos' (no sentido estatístico do termo) com a pressão demográfica e a modernização, ao ponto de invalidar as conclusões sobre os efeitos dos outros dois fatores considerados.

Portanto as forma de produção estão associadas ao processo migratório, acelerando ou retardando, (relativamente) as tendências migratórias globais, em função de que essas forma de produção implicam em diferentes graus de modernização (tanto no sentido da utilização dos itens da tecnologia moderna, quanto no sentido da racionalização capitalista), de resistência à expulsão e de utilização do trabalho.

\section{REGIONALIZAÇÃO DO ESTADO PELAS SUAS FORMAS HISTÓRICAS DE PRODUÇÃO}

Identificar as formas de produção que historicamente têm surgido no Estado, e elaborar uma regionalização permitirá que cada forma esteja representada por uma região. Assim, diferente das análises de migração realizadas até agora, o presente artigo pretende levar em consideração, o processo histórico de formação da organização social agropastoril, como fator explicativo (ou analítico) central.

As formas de produção, de acordo com a definição conceitual já estabelecida, são conjuntos de características que se reproduzem historicamente. Portanto, para se chegar a uma regionalização que possa realmente captar o processo histórico em questão, foi necessário superar a idéia de uma simples divisão do espaço através de técnicas quantitativas ao redor de certas variáveis classificatórias num corte 'vertical' (sincrônico). Em lugar dessa abordagem tradicional, optou-se pela seleção, a partir da literatura, de três regionalizações que se aproximam, no seu cotidiano, do conceito de forma de produção que captam o resultado contemporâneo do processo histórico da gênese das mesmas.

Por 'superposição' dessas regionalizações, chegou-se a uma solução espacial final de sua distribuição no Estado, onde cada região corresponde a uma forma. Esta

\footnotetext{
${ }^{1}$ De posse das três divisões regionais já explicitadas, passou-se à superposição das mesmas. O processo de superposição é feito com lâminas transparentes e segue as etapas seguintes:
} 
regionalização final expressa então, uma interpretação histórica desta evolução. As regiões resultantes são posteriormente utilizadas como conjunto de variáveis nominais com relação as quais se analisa a emigração rural.

\section{Revisão histórica e regionalização teórica}

Antes de tratar das regionalizações mencionadas, há um primeiro aspecto relevante a considerar na organização produtiva da agricultura do Estado: são os condicionantes naturais de ocupação do espaço.

Segundo BRUM (1983), foram três fatores que condicionaram mais fortemente a ocupação do espaço gaúcho pelo elemento branco:

a)a dificuldade de acesso ao litoral que por ser arenoso e aberto, impedia o acesso das embarcações;

b) a inexistência de riquezas comerciáveis, cuja exploração consistia no principal objetivo da ocupação dos novos territórios pelos europeus;

c)a vegetação original, que incluía duas formações distintas: o campo, ocupando $52 \%$ do território e mata, cobrindo os 58\% restantes do atual espaço gaúcho. A influência destas áreas foi decisiva tanto na ocupação, quanto na organização das atividades produtivas do RS. No campo se fixaram os portugueses e na mata os alemães e italianos, principalmente.

O fator que provocou a atração dos portugueses ao campo foi a presença do gado bovino, introduzido pelos jesuítas em 1634 e que ficou abandonado, após a destruição das reduções pelos bandeirantes paulistas. Este gado bovino se multiplicou e se espalhou por toda essa região. Com a criação da Colônia de Sacramento em 1680, foi descoberta a sua existência, e com isso passou a ser caçado e abatido tanto por portugueses quanto por espanhóis em busca do couro, do sebo e das crinas para comercialização com os ingleses e franceses no Estuário do Prata. Já os paulistas,

a) Superposição do mapa de áreas de colonização sobre o de estrutura fundiária para se obter figura A;

b) Superposição do mapa resultante da primeira etapa (Fig A) sobre o de formas de organização da produção agropastoril para se obter a figura B com as FORMAS DE PRODUÇÃO preliminares do RS ;

c) Reajuste das regiões através das análises dos produtos principais de cada região e do uso da terra para obtenção de FORMAS DE PRODUÇÃO FINAL. 
quando descobriram tal riqueza, organizaram tropas para levar este gado até São Paulo e Minas Gerais onde eram vendidos para o abastecimento da população.

A partir de 1732, com a importância econômica adquirida pelo rebanho bovino, o governo começou a distribuir títulos de posse da terra a fim de consolidar sua presença no território. Foram, então, doadas as primeiras sesmarias (propriedades extensas medindo 3 léguas por uma légua cuja extensão podia atingir até 13000 hectares). Surgem, então, as primeiras estâncias de criação, origem do latifúndio pecuarista.

Ainda predominantemente dentro da zona de campo, aparece um outro tipo de propriedade doada, com cerca de $1 / 4$ de légua em quadro, a data, destinada a agricultura e com o objetivo de diversificar a produção, que até então era somente pastoril. Essas datas foram doadas aos açorianos a partir de 1752. Entretanto, fatores como a praga da ferrugem destruindo os trigais, freqüentes guerras contra os castelhanos pela posse do território, convocação dos filhos dos agricultores para a luta e requisição de alimentos e animais sem o ressarcimento justo, levaram os açorianos, aos poucos, a abandonarem a agricultura para se tornarem estancieiros (BRUM, 1988:25). A posse e a concentração da terra lhes assegurava poder. Segundo VIEIRA, o poder que emergia da propriedade da terra era tão forte a ponto de induzir o estancieiro a ampliar seus horizontes em larga escala, formando verdadeiras estruturas feudais, influenciando o poder político e garantindo a defesa da terra (1985:44).

A partir de 1780, com a expansão das charqueadas, cresceu, significativamente a importância econômica do gado, e de 1801 em diante, consolidou-se a ocupação portuguesa na área de campo com a conquista militar das Missões.

Já por volta de 1822, com a área de campo do Rio Grande do Sul totalmente ocupada, e sendo ainda o gado o elemento propulsor da economia gaúcha embasada no binômio criação/charqueada, cresce a necessidade de ocupação das terras de mata. Essas terras possuíam um valor insignificante por não serem adequadas à criação de gado, fonte de prestígio e poder na época e, portanto, foram destinadas aos imigrantes alemães e italianos, principalmente.

Os alemães chegaram a partir de 1824, ocupando inicialmente as áreas de várzea ou próximas aos rios formadores do Guaíba; os italianos chegaram de 1875 em diante e ocuparam a região centro-nordeste do Estado. Os lotes rurais que esses imigrantes receberam sofreram alterações nas suas dimensões com o decorrer do tempo, pois 
iniciaram cada um com 77 hectares até 1851 , desta data até 1889 passaram a medir 48,4 hectares e de 1889 em diante passaram a ter 25 hectares de área (1 colônia de terra).

Desta forma ficam estabelecidos os chamados Grande Domínio (GD) e Pequeno Domínio (PD), que correspondem às duas formas de produção originárias no Estado, a Grande Propriedade (domínio do latifundiário) e a Pequena Produção (domínio do campesinato). Estas formas porém, não ficaram estanques. As forças do capitalismo avançando, e a própria dinâmica interna das formas de produção transformaram parcialmente a organização desse quadro, tanto ocupando os espaços vazios por pequenas e grandes empresas agropecuárias, como transformando algumas fazendas em "grandes propriedades modernizadas" e algumas pequenas produções em "sítios modernizados" (GOODMANN, 1984).

Pode-se, inicialmente, caracterizar a grande propriedade pelo uso de uma mãode-obra semi-servil e escrava, objetivando desenvolver a pecuária de forma extensiva principalmente para a produção de charque exportado para o centro do país. Em contrapartida, a pequena propriedade dedicava-se à produção de alimentos para a subsistência dos camponeses, através do trabalho familiar.

Quanto à pecuária, ao integrar o binômio criação-charqueada, era a atividade primordial do Estado e localizava-se na região fronteiriça. O estancieiro muitas vezes obteve essas terras como recompensa por seus serviços militares e não houve por parte dele preocupação alguma de reinvestir o capital ali produzido e acumulado. "Em vez de investir em reprodutores, a fim de dinamizar o processo de refinamento e seleção do gado, o excedente era aplicado de preferência na aquisição de bens supérfluos e suntuários" (PESAVENTO, 1980: 31). A dependência da economia gaúcha, em relação a economia central também, por sua vez, canalizava os excedentes econômicos para o centro do país.

Já as áreas de colonização, caracterizadas inicialmente por uma agricultura de subsistência cuja localização foi em "terras até então virgens, não aproveitadas pelo latifúndio pecuarista" (PESAVENTO, 1980: 157) apresentaram outro tipo de desenvolvimento. Isto porque, os camponeses ali radicados, passaram a produzir excedentes alimentícios a fim de abastecer os centros consumidores mais próximos. A partir de 1875, a agricultura colonial gaúcha já se tornara especializada na produção desses gêneros que eram exportados para o mercado interno do centro do país, dinamizado pelo desenvolvimento do complexo cafeeiro. Dessa forma, os produtos 
coloniais gaúchos foram adquirindo um peso cada vez maior no comércio interno do país, durante o Império.

Coube assim, ao comércio a maior responsabilidade na capitalização de recursos disponíveis e aplicáveis no processo de industrialização do Estado. A “diversificação das aplicações de capitais, por parte do comércio, constitui o elemento básico para a implantação da indústria no RS" (LAGEMANN, 1980: 134), demonstrando desse modo, uma dinâmica diferente daquela desenvolvida nas áreas de domínio da pecuária latifundiária.

Esta diferenciação histórica estabeleceu os parâmetros básicos das formas de produção no Estado, que perduram nos seus linhamentos básicos até hoje, com diferenças bem marcantes em níveis de desenvolvimento.

Portanto, teoricamente, as formas de produção constituídas no Estado podem ser especificados assim:

- Fazenda Tradicional: ligada ao grande domínio (desenvolvida na área de campo do Estado) dedicada a pecuária extensiva;

- Fazenda Modernizada: resultante da transformação da fazenda tradicional diante das forças do capitalismo, dedicada a produtos dinâmicos (soja, trigo e arroz em conjunto com o gado);

- Pequena Produção Funcional/; ligada à fazenda tradicional através do fornecimento de mão-de-obra, geralmente semi-proletária e que produz alimentos para o auto-consumo, principalmente:

- Pequena Produção Tradicional Colonial: ligada ao pequeno domínio e desenvolvendo uma agricultura de subsistência mas não ligada funcionalmente ao grande domínio;

- Sítio Modernizado: gerado no pequeno domínio e dedicado a uma agricultura moderna, não mais de subsistência.

\section{Regionalização Empírica}

Pergunta-se agora: como então identificar os espaços onde se situam contemporaneamente cada uma dessas FORMAS DE PRODUÇÃO? Foram então selecionados três regionalizações buscando atingir tal objetivo:

a) Regionalização por Áreas de Colonização: regionalização de ROCHE (1969), relativa aos distintos grupos sociais que ocuparam em diferentes épocas o espaço 
gaúcho.É importante destacar que nesta divisão regional ficam discriminadas, nas áreas de povoamento luso-brasileiras, aquelas que já existiam em 1824 e as que surgiram no período entre 1824 -1872. Também em relação à colonização alemã, estão destacadas as áreas das colônias velhas alemãs daquelas que surgiram após 1914, bem como da área de colonização italiana. Homogeneizando todas as áreas de colonização italiana, de um lado, e de outro as áreas de povoamento luso-brasileiras, é possível, observar duas formas distintas de ocupação do espaço sulriograndense: a primeira, luso-brasileira caracterizada pela presença das grandes propriedades fundiárias, cuja origem remonta ao século XVIII, quando da concessão das primeira sesmarias; e a segunda, teutoitaliana constituída pelas pequenas propriedades camponesas, diretamente relacionada com a imigração.

Porém, só esta regionalização básica de ROCHE, determinante do estabelecimento dos chamados Grande e Pequeno Domínios, não é suficiente para captar o fenômeno em questão. Como foi indicado anteriormente, algumas evoluções importantes tem modificado esse quadro. Assim, áreas de ocupação inicialmente lusa, foram posteriormente reocupadas por camponeses oriundos das colônias e mais recentemente, a lavoura empresarial foi ocupando extensas áreas do Estado.

Considerando estas alterações significativas na organização social da produção, optou-se por outras duas regionalizações existentes na literatura: estrutura fundiária e formas da organização agropastoril.

b) Regionalização por Estrutura Fundiária: a partir da consideração de que as formas de produção estão estreitamente associadas à estrutura fundiária, decidiu-se incluir esta distribuição fundiária na regionalização, como um indicador adicional do mesmo fenômeno básico.

Os dados de estrutura fundiária permitiram identificar quatro conjuntos distintos de municípios do Estado. O primeiro, onde a área ocupada pelas grandes propriedades é superior a $66 \%$ da área total de cada município, enquanto que as pequenas não chegam a ocupar 10\% desta mesma área total (Campanha Gaúcha). Também foi identificado um segundo grupo onde não há uma predominância de pequenas, médias ou grandes propriedades ou seja há uma certa distribuição regular (Planalto e Depressão Central). O terceiro grupo de municípios tem com predominância propriedades pequenas que ocupam mais de $50 \%$ da área total do município enquanto que as grande propriedades não chegam a ocupar 15\% desta área total (Encosta do Planalto e Alto Uruguai)). No 
quarto grupo há uma predominância das grandes propriedades com cerca de $50 \%$ da área total enquanto que as pequenas ficam com cerca de $20 \%$ desta mesma área (Campos de Cima da Serra, Missões, Planalto Uruguaio Sulriograndense e Litoral).

Esta estrutura fundiária associada à regionalização por formas de produção da organização agropastoril possibilitará estabelecer uma relação entre relações de trabalho e tamanho da propriedade.

c) Formas de Organização da Produção Agropastoril: a utilização da regionalização do Estado realizada por KUCHEMANN (1980) divide o Estado, de acordo com a denominação da autora, em "formas de organização da produção agropastoril", distinguindo três áreas: a agropecuária colonial, a lavoura empresarial e a pecuária tradicional. Estas correspondem, grosso modo, ao Grande e Pequeno Domínios e a uma área de transição existente entre eles. Esta última representa historicamente a primeira fronteira utilizada pelos investidores na agricultura.

KUCHEMANN (1980) utilizou critérios que estabelecem, empiricamente cada uma dessas áreas. Para a "pecuária tradicional" considerou toda a área constituída por latifúndios, introduzidos pelos portugueses, onde o fator terra tem elevada participação no processo produtivo, enquanto os fatores capital e trabalho apresentam baixa participação nesse processo. Também considerou a presença do trabalho assalariado; que o destino da produção de bovinos e ovinos é tanto o mercado externo quanto o interno; que a produtividade econômica é baixa em relação aos outros domínios, e finalmente que há uma crescente decência de terras para a lavoura empresarial através de concessões temporárias (parceria e arrendamento).

Para a "lavoura empresarial", considerou as áreas onde há uma combinação harmônica entre os três fatores de produção (capital, terra e trabalho), com um certo predomínio do fator capital sobre os demais. Também nessa região, o trabalho assalariado é predominante; a produção (arroz, trigo e soja principalmente) destina-se muito mais para o mercado externo que para o interno; o tamanho das propriedades variam entre média e grande e, é comum a parceria e o arrendamento. A taxa de crescimento é elevada em relação ao domínio da pecuária tradicional.

Em relação à "agropecuária colonial”, a autora considerou as áreas de domínio do minifúndio onde o fator força de trabalho predomina sobre os fatores capital e terra. Ao contrário dos domínios anteriores, o trabalho desta região é familiar, desenvolvendose em propriedades com um tamanho médio de 14 hectares; a produção agrícola é 
diversificada ao lado da pecuária de pequeno porte (leiteira), destinando-se para o autoconsumo principalmente, e também para os mercados interno e externo (mais raramente este último).

Considerando-se pois as três regionalizações chegou-se à regionalização por formas de produção estabelecidas teoricamente considerando, o fator ocupaçãocolonização, em seguida à estrutura fundiária e por último à organização da produção agropastoril. O que se observou é que quando há uma clareza no que se refere a estrutura fundiária da região se torna simples relacioná-la com a forma de produção teórica. É este o caso das áreas onde domina o latifúndio bem como das áreas onde domina a pequena propriedade, onde uma análise da produção vai permitir especificar com maior nitidez a forma de produção dominante e assim relacioná-la ao processo emigratório do Estado.

É importante destacar que pelo fato das regionalizações terem sido elaboradas para outros propósitos, a metodologia aqui utilizada poderia ainda levar a algumas distorções. Para levar em consideração esta possibilidade e corrigir os outros erros que por ventura pudessem existir nas regionalizações anteriores, a primeira versão da regionalização (10 regiões), passou por um processo de depuração, elaborado a partir da análise da produção e do uso da terra em cada município.

Dessa forma, chegou-se à regionalização final por formas de produção constituída por sete regiões, cinco das quais diretamente relacionadas com as formas de produção teoricamente estabelecidas e duas que, por sua indefinição quanto a estrutura fundiária não permitiram qualquer relação Esta regionalização, então, vai se constituir na base explicativa para a análise da emigração rural do Rio Grande do Sul, ficando assim constituída ${ }^{2}$ :

Região 1: FAZENDA TRADICIONAL DO GRANDE DOMÍNIO (pecuária tradicional, domínio do latifúndio, colonização luso-brasileira);

Região 2:LAVOURA EMPRESARIAL DO GRANDE DOMÍNIO (agricultura modernizada, monocultura, domínio do latifúndio, colonização luso-brasileira);

Região 3: Pequena ProduÇão Funcional do Grande Domínio (agricultura tradicional, policultura, domínio do minifúndio, colonização luso-brasileira);

\footnotetext{
${ }^{2}$ Nesta regionalização os municípios que compõem a área metropolitana de Porto Alegre não foram considerados uma vez que suas características urbano-industriais são significativamente mais fortes do que as características agrárias.
} 
Região 4:LAVOURA CAPITALISTA DE DOMÍNIO Misto (agricultura modernizada, monocultura, estrutura fundiária mista, colonização luso-brasileira);

Região 5:AgropecuÁria COlONIAL DO PEQUeno Domínio (agricultura tradicional, policultura, domínio do minifúndio, colonização teuto-italiana);

Região 6:LAVOURA EMPRESARIAL DO PEQUENO DOMÍNIO (agricultura modernizada, monocultura, domínio do minifúndio, colonização teuto-italiana);

Região 7:LAVOURA CAPITALISTA DE DOMÍNIO Misto (agricultura modernizada, monocultura, estrutura fundiária mista, colonização teuto-italiana).

Esta regionalização tem um caráter histórico embutido em sua formação. A presença dos elementos organizacionais historicamente gerados é fundamental para melhor se compreender a emigração rural no Rio Grande do Sul.

\section{As formas de produção e a emigração rural}

Com essa regionalização definitiva elaborada a partir das diferentes formas produtivas do Estado, já se torna possível relacionar as formas de produção à emigração rural ou seja sua relação com a aceleração e com a desaceleração desse processo.

É necessário indicar que estas regiões são diferenciadas entre si a partir de uma pluralidade de fatores, portanto, não existe um fator único que explique a aceleração e a desaceleração do processo emigratório.

Fig. 1 


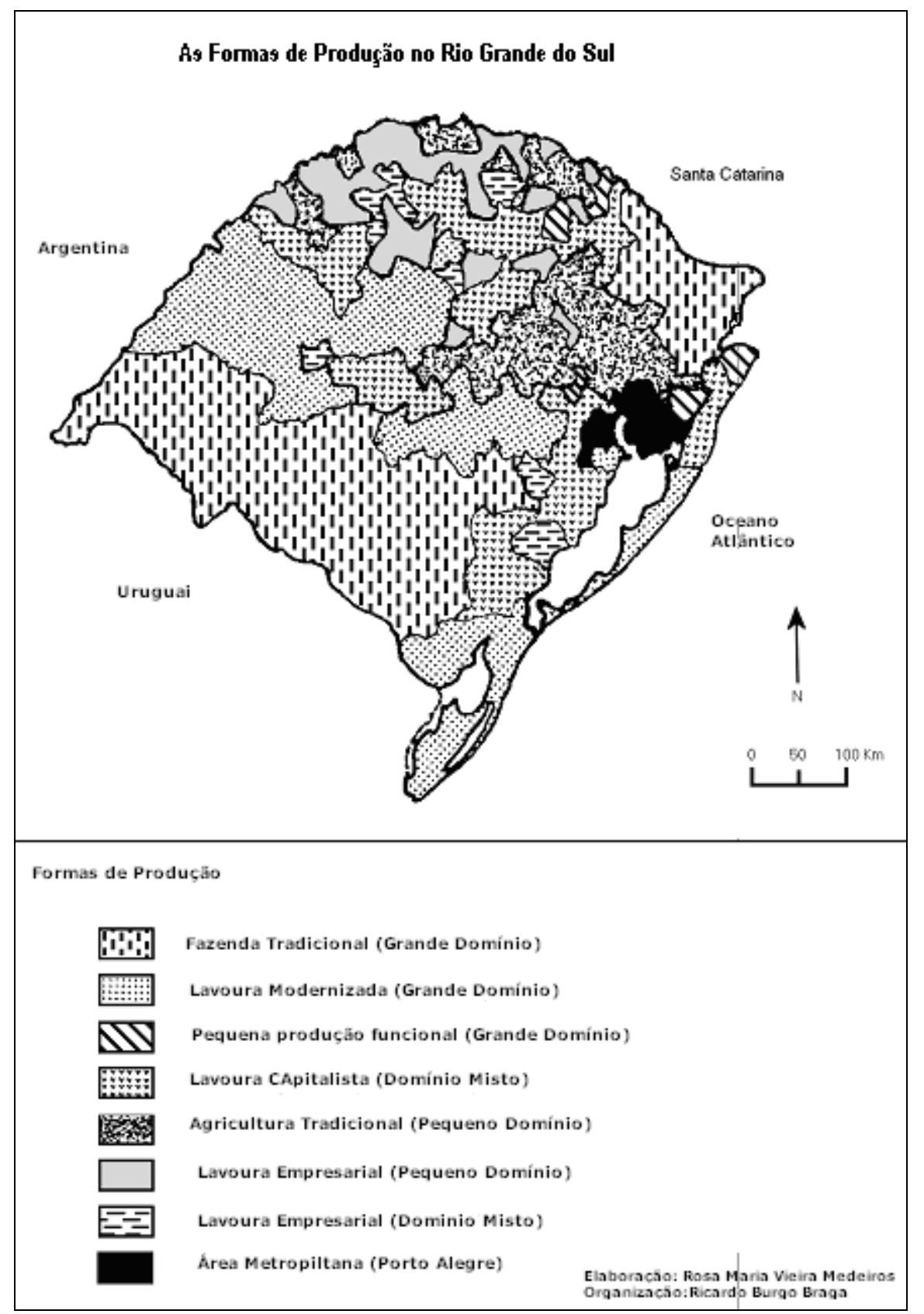

Considerando que o modelo conceitual utilizado tem como base da análise para estes fatores de expulsão, o fator demográfico e o fator modernização capitalista (FANDINO, 1978) é importante ressaltar como os mesmos se efetivam.

O fator demográfico efetiva-se a partir da alteração na relação homem-terra diante da saturação relativa dos limites de sobrevivência das populações rurais, associada a sua estrutura fundiária (FANDINO, 1978: 40). A pressão demográfica nas áreas rurais não acontece, porém, somente a partir de um fracionamento por herança no minifúndio, mas também nas áreas de domínio da grande propriedade, em função da 
pouca atividade dominante, a pecuária extensiva, que exige pouca mão-de-obra. Esta mão-de-obra, ao se reproduzir, só tem como alternativa migrar.

O fator modernização capitalista, por sua vez, se efetiva a partir do uso intensivo, ao nível de unidades produtoras, de insumos industriais - máquinas, equipamentos e produtos químicos - bem como utilização de métodos e técnicas de preparo e cultivo do solo de tratos mais sofisticados com o predomínio do fator capital sobre os demais. Este processo de modernização se desenvolve tanto em áreas do Pequeno Domínio quanto do Grande Domínio, ou seja atua em formas de produção distintas. Em termos teóricos é possível então, afirmar que:

a) Na agricultura tradicional do Pequeno Domínio, a emigração sofre uma 'desaceleração relativa' (com relação a outras formas de produção), pela ausência de modernização. Esta forma de produção permite o fracionamento quase limitado da terra e o desemprego disfarçado;

b) Na lavoura empresarial do Grande Domínio a emigração rural sofre uma desaceleração relativa provocada pela modernização, em função da procura de mão-deobra gerada na passagem da pecuária extensiva para a lavoura empresarial;

c) Na lavoura empresarial do Pequeno Domínio, a emigração rural sofre uma aceleração relativa, pela modernização, em função da sua maior racionalidade econômica capitalista, a qual é oposta ao fracionamento quase ilimitado da terra com o desemprego disfarçado, próprios da pequena produção tradicional;

d) $\mathrm{Na}$ fazenda tradicional do Grande Domínio, a emigração rural, dada uma população majoritariamente proletária ou semi-proletária, sofre uma aceleração relativa pela pressão demográfica, em função da inelasticidade das oportunidades de emprego, (especialmente pela impossibilidade de emprego disfarçado).

Com relação às regiões de Lavoura Capitalista Domínio Misto e a região da Pequena Produção Funcional do Grande Domínio, não é possível estabelecer pressupostos teóricos concretos, pelas dificuldades de especificar os fatores analíticos.

\section{CONSIDERAÇÕES FINAIS}

A análise dos dados de produção município por município associada às taxas de migração calculadas também, para cada município possibilitou identificar diferenças significativas entre a emigração rural ocorrida na Fazenda Tradicional do Grande Domínio e a Agricultura Tradicional do Pequeno Domínio, que emergem também da análise histórica. 
Considerando que Agricultura Tradicional do Pequeno Domínio (região 5), tem como característica básica a pequena propriedade o que se constatou é que a possibilidade de fracionamento da terra tende a neutralizar o impacto da pressão demográfica na migração. Esta neutralização é possibilitada também pela policultura de subsistência e comercial a que se dedicam os pequenos produtores, no sentido de que podem tolerar níveis de subemprego muito altos, em função de terem garantida a sua sobrevivência mínima a partir dos produtos colhidos na propriedade.

Em segundo lugar, a Agricultura Tradicional do Pequeno Domínio, ao desenvolver uma atividade agrícola intensiva, faz uso de toda a mão-de-obra disponível na propriedade, e inclusive encobre um certo grau de desemprego disfarçado. Isto se dá em função de que esta pequena produção não apresenta características que permitam qualificá-la de moderna, no sentido de que o lucro não é o fator predominante, ou pelo menos, a sobrevivência familiar está acima da simples racionalidade do trabalho. Então, de certa forma, pode-se dizer que uma super abundância de mão-de-obra nas pequenas propriedades, e conseqüentemente níveis altos de desemprego disfarçado ou subemprego, não toleráveis em empresas puramente capitalistas, são parcialmente tolerados no caso da pequena produção em questão.

Quanto a Fazenda Tradicional do Grande Domínio (região 1), de acordo com a descrição já feita para formas de produção, sua principal característica é a presença marcante do latifúndio onde se desenvolve preferencialmente a pecuária extensiva.

Nesta região há um parcelamento de terra relativo entre os grandes produtores, mas que não implica em incremento da emigração da população local, no caso os fazendeiros. Porém o mesmo não acontece quando as famílias dos trabalhadores das fazendas se reproduzem, pois a tendência é geralmente migrar. Isto porque eles não possuem minifúndios policultores de efeito retentivo como possui a Agricultura Tradicional do Pequeno Domínio Além disso, está forma de produção além de não utilizar técnicas modernas que envolvem maiores investimento de capital e que poderiam absorver uma certa quantidade de mão-de-obra, na sua forma atual tradicional, necessita de pouco trabalho.

É interessante salientar aqui, que a ausência da modernização nestas duas formas de produção, demonstram que o fator que atua sobre a migração desta população rural é apenas o fator demográfico. 
Assim pois, considerando que este fator demográfico se caracteriza justamente pela relação entre a disponibilidade de terra, o trabalho e a população, o que se verifica nas duas formas de produção anteriormente analisadas, é que:

a) na Fazenda Tradicional do Grande Domínio, enquanto há uma grande quantidade de terras disponíveis para a atividade dominante (pecuária), o mesmo não acontece com o trabalho, que tendo pouca demanda, torna a população rural excedente, acelerando a sua saída;

b) na Agricultura Tradicional do Pequeno Domínio, enquanto houver a diversificação da produção absorvendo a mão-de-obra através de diferentes formas e a possibilidade futura de um parcelamento que ainda permita produzir para a sobrevivência da família, há uma desaceleração da emigração de sua população. No entanto a prática da monocultura associada a impossibilidade de parcelamento da terra devido ao seu tamanho já reduzido, vai provocar uma forte emigração ou seja vai atuar como forte fator de expulsão.

Há que se considerar que a lavoura modernizada do Grande Domínio pode tender a desacelerar o processo emigratório, provavelmente em função das novas necessidades adicionais de mão-de-obra, em comparação com a atividade anterior, a pecuária extensiva, que a precedeu historicamente. Inversamente, a lavoura modernizada do Pequeno Domínio surge historicamente de um contexto onde a oferta de mão-de-obra é muito maior, e onde a tendência é a racionalização do trabalho. Portanto, as taxas emigratórias devem subir com relação as da lavoura modernizada do Grande Domínio.

O fator modernização, ausente nas formas de produção, Fazenda Tradicional do Grande Domínio e Agricultura Tradicional do Pequeno Domínio, permite concluir que:

a) sua presença numa região de domínio do latifúndio aparentemente provoca transformações no que se refere a oferta de trabalho para a população rural, justamente em função do desenvolvimento de uma nova atividade, a agricultura modernizada, desacelerando a emigração rural.

b) seu efeito na população rural da região do Pequeno Domínio é de aceleração da emigração, pois na medida em que o processo de modernização vai se desenvolvendo na pequena produção, a tendência de sua população rural é emigrar, já que o parcelamento das terras não se torna mais possível e a absorção de mão-de-obra se torna restrita. 
Ao nível da política agrícola e de Reforma Agrária em particular, as conclusões anteriores permitem prever que a viabilização da modernização da agricultura do Pequeno Domínio via crédito, via assistência técnica, subsídios para comercialização, etc., produziu um impacto emigratório significativo. Porém, por outro lado, a distribuição de terras no Grande Domínio (latifúndio), complementada pela viabilização de uma pequena agricultura moderna fazendo uso das políticas agrícolas mencionadas, teria como efeito demográfico uma absorção igualmente significativa de população, compensando em alguma medida o efeito expulsivo ocorrido na agricultura modernizada do Pequeno Domínio.

É importante destacar a importância do desenvolvimento de uma policultura no Pequeno Domínio, em moldes diferentes dos processos de modernização, na forma como acontecem hoje. Esta conclusão não é nova, mas não tinha sido estabelecida empiricamente nos termos específicos do contesto do Estado. Inversamente pode-se salientar a importância, na fixação do homem à terra, da própria modernização, porém, aplicada no contexto do latifúndio pecuarista.

O presente artigo mostra a forte tendência da emigração rural que sofrem uma modificação segundo as formas produtivas e de acordo com as combinações específicas dos fatores demográficos, fundiário e modernizacional de cada forma.

Ao nível da teria geral da emigração rural e dos seus fatores causais (genericamente considerados), é possível, diante do que foi observado, concluir que:

a) a pressão demográfica e a modernização das formas produtivas não tem um tipo único de efeito migratório (positivo ou negativo) pois em cada uma das regiões, tem efeitos diferenciados de aceleração ou de retração da emigração rural.

b) em função da conclusão anterior, a aceleração da emigração da população rural não acontece somente na presença do fator modernização, ocorre também na ausência desse fator desde que exista pressão demográfica. Mais ainda, a emigração pode acelerar-se em função da modernização, desde que exista pressão demográfica.

c) um aspecto ainda não mencionado ao nível de conclusões e que possui uma grande importância metodológica, é a relevância da ocupação histórica do RS como estratégia de análise. A importância desse aspecto está justamente no fato de que, é a partir das formas produtivas presente historicamente no Estado, que se chegou a identificação das combinações de fatores migratórios particulares a sua realidade e que tem ainda hoje conseqüências demográficas e sócio-econômicas profundas. 


\section{BIBLIOGRAFIA}

AMIM, Samir e VERGOPOULOS, Kostas. A questão Agrária e o Capitalismo. Paz e Terra, Rio de Janeiro, 1977.

BAGU e PALERMO in: MUNOZ, Humberto e OLIVEIRA, Orlandina A Migração Interna na América Latina: exposição crítica sobre algumas análises. In: Migração Interna; textos selecionados. Ministério do Interior, Bando do Nordeste do Brasil, 1980.

BRUM, Argemiro J. Modernização da Agricultura - trigo e soja. Vozes, Petrópolis, 1988.

CARVALHO, José. Migrações Internas: Mensuração Direta e Indireta. ABEP, Belo Horizonte, 1980.

FANDINO, Juan M. Determinantes Econômicos e Sociológico da Migração Ruralurbana: ensaios de uma metodologia de análise de resíduos migratórios. Revista de Economia Rural. 1978, v. 16. N. 2.

FRIEDMANN, Harriet. Household Productiona and the National Economy: concepts for the Analysis of Agrarian Formations. The Journal of Peasant Studies. 1980, v. 7 , n.2.

GOODMANN, D. et alli. Agroindústria, Política Pública e Estruturas Sociais Rurais: Análises recentes sobre a Agricultura Brasileira. Revista de Economia Política, 1984, v.5, n.4.

IBGE. CENSO DEMOGRÁFICO: 1950, 1960, 1970 e 1980.

KAUTSKY, Karl. A Questão Agrária. Portucalense, Porto, 1972.

KUCHEMANN, Berlindes A. O Minifúndio Gaúcho. UCS, Caxias do Sul, 1980. 
LAGEMANN, Eugenio. Imigração e Industrialização. RS: Imigração e Colonização. Mercado Aberto, Porto Alegre, 1980.

MARX, Karl. O Capital. edição resumida. Zahar, Rio de Janeiro, 1980.

Migrações Internas no RS - INDICADORES SOCIAIS RS. Número Especial, FEE, 1976, Porto Alegre.

MOREIRA, I. A. G. e COSTA, R. H. Espaço e Sociedade no Rio Grande do Sul - Série Revisão. Mercado Aberto, Porto Alegre, 1982.

OSÓRIO, Carlos. Migrações Recentes e Desigualdades. In: Migração Interna; textos selecionados. Ministério do Interior, Bando do Nordeste, 1980.

PESAVENTO, S. J. A República Velha Gaúcha. Movimento, Porto Alegre, 1980.

PROGRAMA DE INVESTIMENTOS INTEGRADOS PARA O SETOR AGROPECUÁRIO. Atlas de Regionalização e Zoneamento Agrícola do Rio Grande do Sul - Estudos Básicos. Porto Alegre, 1976, v. 6.

ROCHE, Jean. A Colonização Alemã e o Rio Grande do Sul. Globo, Porto Alegre, 1969.

SALAMINI, L. The Sociologic of Political Praxis - na introduction to Gramsci's Theory. Routledge \& Kegan Paul, London, 1981.

SECRETARIA DA SAÚDE. Sub Registros de Óbitos e de Nascimentos do Rio Grande do Sul. Porto Alegre, 1974.

SECRETARIA DA INDÚSTRIA E COMÉRCIO. Turismo RS/4 - Subsídios para a Regionalização Turística do Estado. Porto Alegre, 1986.

SINGER, Paul. Migrações Internas: considerações teóricas sobre o estudo. In: Migração Interna; textos selecionados. Ministério do Interior, Banco do Nordeste, 1980. 


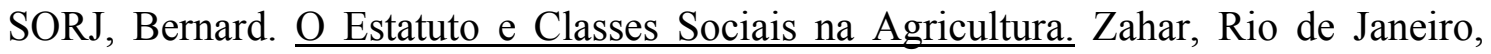
1982.

SOUZA, Itamar. Migrações Internas. Vozes, Petrópolis 1980.

VIEIRA, Eurípedes F. Rio Grande do Sul - Geografia da População. Sagra, Porto Alegre, 1985 